\title{
Alcohol consumption: monitoring, regulation and impact on public health
}

\author{
Jo Mitchella,b,f and Adrian Dunlop p,c,d,e \\ ${ }^{a}$ Centre for Population Health, NSW Ministry of Health, Sydney, Australia \\ b Guest Editor, Issue 4, 2016 \\ 'School of Medicine and Public Health, University of Newcastle, NSW, Australia \\ d Hunter Medical Research Institute, Newcastle, NSW, Australia \\ e Hunter New England Local Health District Drug and Alcohol Clinical Services, Newcastle, NSW, Australia \\ ${ }^{\dagger}$ Corresponding author: jmitc@doh.health.nsw.gov.au
}

\section{Article history}

Publication date: September 2016 Citation: Mitchell J, Dunlop A. Alcohol consumption: monitoring, regulation and impact on public health. Public Health Res Pract. 2016;26(4):e2641640. doi: http:// dx.doi.org/10.17061/phrp2641640
The recently released Report of the Chief Health Officer of New South Wales (NSW), Australia, presents information on alcohol consumption from the perspective of drinking frequency, harmful drinking, nondrinkers and health impacts. ${ }^{1}$ The report shows that alcohol consumption continues to have a significant impact on individual and population health and healthcare systems, as it does in many other parts of Australia and the world. There is also an economic impact - the Foundation for Alcohol Research and Education has estimated this cost at $\$ 36$ billion per year across Australia. ${ }^{2,3}$ This issue of Public Health Research \& Practice explores the role and outcomes of monitoring and regulation of alcohol consumption, as well as avenues for reducing alcohol-related harm.

Our themed articles include a Perspective that considers why young people in NSW are consuming less alcohol and choosing to start drinking later in life. Moore and colleagues describe a range of factors in play, such as reductions in supply, taxation and, potentially, changes in leisure activities. Another Perspective describes the significant prevalence of alcohol and other drug problems in hospital emergency departments, and describes the costeffective impact that hospital drug and alcohol consultation liaison services can make. Haber and Morley describe another, often overlooked, approach to reducing alcohol-related harm. They argue that alcohol anti-craving medicines can improve the management of alcohol dependence, and should be more widely prescribed.

Trading hours for licensed premises continue to spark media attention in Australia, with ongoing debates for and against any restrictions to alcohol consumption. In a systematic review, Wilkinson and colleagues examine the positive impacts of changes to trading hours of liquor licences on alcoholrelated harm in Australia and internationally.

In another Research article, Johnson and colleagues discuss the potential for a personalised genetic susceptibility feedback intervention to motivate alcohol behaviour change. And in the last of the themed papers, Moore and colleagues describe the development of an innovative telephone coaching service in NSW to assist adults to improve their health by reducing alcohol consumption. 
Other papers in this issue include a Research article that examines the potential effect of living in a house with loose-fill asbestos insulation, and describes mesothelioma trends in the Australian Capital Territory compared with the rest of Australia. Johnson and colleagues describe Cancer Council Western Australia's campaign to fight unproven breast cancer screening and stem the unregulated growth of alternative breast imaging services. And finally, Lloyd and colleagues describe the development of a health risk assessment tool for use in workplaces that could help to identify workers who are at risk of chronic disease and refer them to healthy lifestyle programs.

Thank you to all our readers for your support since Public Health Research \& Practice launched in November 2014. We aim to deliver engaging, high-quality, peerreviewed articles from Australian and international thought leaders, policy makers, practitioners and researchers that will inspire, provoke debate and be useful in your work. Please encourage your colleagues to submit articles, subscribe to our quarterly email and follow us on Twitter (@phrpjournal).WWe invite you to make suggestions about themes or topics and send us your feedback, make suggestions about themes or topics and send us your feedback.

\section{Competing interests}

AD is seconded by the NSW Ministry of Health to work as the Chief Addiction Medicine Specialist. Payment is to his employer, the Hunter New England Local Health District.

\section{References}

1. NSW Ministry of Health. Trends in alcohol use and health-related harms in NSW: report of the Chief Health Officer 2016. Sydney: NSW Ministry of Health; 2016 [cited 2016 Sep 10]. Available from: www.health.nsw.gov.au/ hsnsw/Publications/chief-health-officers-report-2016.pdf

2. Laslett A-M, Catalano P, Chikritzhs T, Dale C, Doran C, Ferris $\mathrm{J}$, et al. The range and magnitude of alcohol's harm to others. Canberra: Alcohol Education and Rehabilitation Foundation; 2010 [cited 2016 Sep 10]. Available from: www.fare.org.au/wp-content/uploads/research/TheRange-and-Magnitude-of-Alcohols-Harm-to-Others.pdf

3. Collins DJ, Lapsley HM. The costs of tobacco, alcohol and illicit drug abuse to Australian society in 2004/05. Canberra: Commonwealth of Australia; 2008 [cited 2016 Sep 22]. Available from: www.health.gov.au/internet/ drugstrategy/publishing.nsf/Content/34F55AF632F67B70 CA2573F60005D42B/\$File/mono64.pdf

\section{Copyright: (c) (i) (2)}

(C) 2016 Mitchell and Dunlop. This article is licensed under the Creative Commons Attribution-NonCommercial-ShareAlike 4.0 International Licence, which allows others to redistribute, adapt and share this work non-commercially provided they attribute the work and any adapted version of it is distributed under the same Creative Commons licence terms. See: www.creativecommons.org/licenses/by-nc-sa/4.0/ 